\title{
Knowledge, Awareness and Attitudes About Research Ethics among Faculty and Post Graduate Students of the Medical \& Dental Professionals in Professional Institutions
}

\author{
Shivananda S. ${ }^{1}$, Vidya G. Doddawad ${ }^{2}$, Ravi Vaswani ${ }^{3}$ \\ ${ }^{1}$ Associate Professor, Department of Oral and Maxillofacial Surgery, JSS Dental College and Hospital, A \\ Constituent College of JSS Academy of Higher Education \& Research, Mysore-570022, ${ }^{2}$ Associate Professor, \\ Department of Oral Pathology and Microbiology, JSS Dental College and Hospital, A Constituent College of JSS \\ Academy of Higher Education \& Research, Mysore-570022, ${ }^{3}$ Former Registrar, Professor, Department of Internal \\ Medicine, Yenepoya Medical College, A Constituent College of Yenepoya University, Mangalore-575018
}

\begin{abstract}
Introduction: The research ethics plays a very vital role in the collection, analysis, reporting and publication of details about research subjects, in particular active acceptance of participant's right to privacy, confidentiality and the informed consent of the participant.
\end{abstract}

Aims: To assess the Knowledge, awareness and attitudes about research ethics among the faculty and students of medical and dental colleges and the requirement for a regular teaching about research ethics among the faculty and students of medical and dental colleges.

Materials and Method: A cross-sectional study was conducted by assessing the responses to 39 selected basic questions regarding Knowledge, awareness and attitudes about research ethics among a total of 415 faculty members and post graduate students of the medical and dental institutions in Mysore city of Karnataka state. The online questionnaire was created by using Google forms. The questionnaire was made into 5 categories. Chi-square tests was used to determine, in bivariate analyses, the association of each of the independent variables. The students t-test was done to assess the respondents scores on the 5-point Likert scale ranging from 1 to 5 . The average of their scores were compared among the various variable like their specialty and academic position by using the ANOVA test.

Results: A total of 415 responses were obtained from the participants of the study. The response tabulated under various sections clearly showed deficiency in the understanding of research ethics. The $\mathrm{P}$ value was kept at 0.05 for this study.

Conclusion: The participants of the questionnaire survey showed that the institutional ethics committees would be very useful for promoting health research and are imperative for appraisal of the health research projects. The requirement for a regular teaching about research ethics among the faculty and students of medical and dental colleges is very important. Further study in this area is very much needed.

Keywords: Research ethics, Knowledge, Awareness and attitudes, Students, Faculty, Professional college.

\section{Corresponding Author:}

\section{Dr. Vidya G. Doddawad}

Associate Professor, Department of Oral Pathology and Microbiology, JSS Dental College and Hospital, A Constituent College of JSS Academy of Higher

Education \& Research, Mysore-570022

e-mail: drvidyagd@gmail.com

Phone No.: +919343830621

\section{Introduction}

Research is defined as the systematic investigation into and study of the materials and sources in order to establish facts and reach new conclusions. It consists of three steps: to pose a question, to collect data to answer the question and to present an answer to the question. 
The research ethics provides guidelines to apply moral regulations and professional codes of conduct in the various steps of research ${ }^{2}$. The research ethics provides guidelines for the responsible performance of research on human participants.

Need for the Study: Good Knowledge about research ethics among the faculty and PG students in Health Institutions has become very important for the benefit of researcher $\&$ his team, to provide good quality of ethically made research not only for the benefit of the participants of the study, but for the whole humanity ${ }^{5}$.

Research Question/Hypotheses: What is the knowledge and awareness about research ethics among the among faculty and post graduate students of the medical \& dental professionals in professional institutions?

How much ethics in research is being practiced among the faculty and post graduate students of the medical \& dental professionals in professional institutions in their speciality?

Materials and Method: Out of 800 available sample size about 415 faculty members and 385 post graduate students of the medical and dental institutions in Mysore city of Karnataka state were included in the study group.

Source of Data: The faculty and post-graduate students of various dental and medical colleges in Mysore city of Karnataka state.

Inclusion Criteria: The faculty and the post graduate students of Institutions in Mysore city of Karnataka state who are interested to participate in the online questionnaire study.

Exclusion criteria: The participants who are not willing to give written the consent to answer the questions in the online questionnaire.

Study design and settings: The responses to 39 selected basic questions regarding Knowledge, awareness and attitudes about research ethics among a total of 415 faculty members and post graduate students of the medical and dental institutions in Mysore city of Karnataka state.

A link for answering the online questionnaire survey was sent to the Head of the Institution/Principal through an email and were requested to circulate the link for the study to all the faculty and post-graduate students of his/ her dental or medical Institutions.

The participants of the online questionnaire survey were allowed at any time to withdraw from the questionnaire study before submitting their response.

To protect the confidentiality of the participant, the survey did not contain any type of information that will personally identify the participant like their email ID, name, designation or the name of their Institute.

The questionnaire was made into 5 categories. Before beginning the questionnaire, the in the first category we had set of questions to collect the demographic information of the participants like age, gender, academic position, prior participation in human research subjects, number of research projects involved in and their prior training in research ethics.

The second part of the questionnaire was used to assess the participants self-awareness towards ethical principles and functions of the ethical committees.

In the third part of the questionnaire the respondents were asked to choose their response about research ethics committee from a 5-point Likert scale ranging from 1 to 5 .

In the fourth part the respondents were asked again choose from the 5-point Likert scale regarding their attitudes towards practicing of research like obtaining the informed consent from the participant, the involvement of vulnerable individuals in their study, confidentiality and conduct of research in a responsible manner.

The fifth part of questionnaire had questions regarding assessment of knowledge about research ethics with questions on case scenarios.

The data was collected and stored in a password protected electronic format.

This study was a self-funded by the Principle Investigator and the participants were not given any kind of monetary benefits for their participation.

Timeline for the study: The online questionnaire survey will be carried out for a period of three months from September to October 2018.

Statistical analysis: The Chi-square tests was used to determine, in bivariate analyses. The students t-test was done to assess the respondents scores on the 5-point 
Likert scale ranging from 1 to 5 . The average of their scores were compared among the various variable like their speciality and academic position by using the ANOVA test. The $\mathrm{P}$ value was kept at 0.05 for this study.

\section{Results}

A total of 415 responses were obtained from the participants of the study. Out of this we had 273 respondents as female and 142 respondents as male. Among these 225 respondents were from the medical speciality and 190 were from the dental speciality.

The results obtained are tabulated in the Graph 1 and table no 1 to 3 .

\section{Proportion of the Academic position}



Academic Position

Graph No. 1: The proportion of the academic position of the respondents is representation

Table No. 1: The responses to details regarding involvement of the respondents in research ethics earlier

\begin{tabular}{|c|c|c|c|c|}
\hline \multirow{2}{*}{ S No } & \multirow{2}{*}{ Knowledge based questions } & \multicolumn{3}{|c|}{ Response percentage } \\
\hline & & $\%$ Yes & $\%$ No & $\%$ Not sure \\
\hline 1 & $\begin{array}{l}\text { Absolute necessary take the informed consent from the patient before doing any } \\
\text { research involving human subjects }\end{array}$ & 93.6 & 4.3 & 2.1 \\
\hline 2 & $\begin{array}{l}\text { Absolute necessary to take an informed consent/assent from the patient/guardian before } \\
\text { doing any research involving Children }\end{array}$ & 97.9 & 2.1 & 00 \\
\hline 3 & $\begin{array}{l}\text { Necessary to get ethical committee approval before doing a retrospective research } \\
\text { involving tissue samples for clinical purposes }\end{array}$ & 85.1 & 4.3 & 10.6 \\
\hline 4 & Need to keep the participants details very confidential while doing a research study & 100 & 00 & 00 \\
\hline 5 & $\begin{array}{l}\text { Need to obtain an approval from the ethical committee before doing any type of } \\
\text { research on human subjects }\end{array}$ & 100 & 00 & 00 \\
\hline 6 & $\begin{array}{l}\text { Need to obtain an approval from the ethical committee before doing any type of } \\
\text { research involving retrospective study of patient's data or investigation reports }\end{array}$ & 83 & 4.2 & 12.8 \\
\hline
\end{tabular}


Table 2: The respondents to the knowledge and awareness-based questions on research ethics

\begin{tabular}{|c|l|c|c|c|}
\hline \multirow{2}{*}{ S No } & \multirow{2}{*}{ The details regarding involvement in priorresearch ethics expressed as } & \multicolumn{3}{|c|}{ Response percentage } \\
\cline { 3 - 5 } & & \% Yes & \% No & \% Not sure \\
\hline 1 & Done research involving human subjects earlier. & 70.2 & 29.8 & NA \\
\hline 2 & Done research involving human biological samples earlier & 55.3 & 44.7 & NA \\
\hline 3 & Had undergone any training in research ethics before & 66 & 34 & NA \\
\hline 4 & Familiar with ethical principles in human subject research & 76.6 & 4.3 & 19.1 \\
\hline 5 & Familiar with the functions of a research ethics committee in their Institutions & 83 & 6.4 & 10.6 \\
\hline
\end{tabular}

The responses to attitudes towards the research ethics committees and research ethics education. We can clearly observe here that most of the respondents suggest that the research ethics should be taught as a mandatory postgraduate module and the members of a research ethics committee should receive training in research bioethics and also all investigators should have some training in research ethics.
The participants responses to attitudes regarding practices in research ethics, was a bit surprising to know that the response to the question of getting informed consent from patients is necessary for use of their biological samples in research showed mixed response, wherein many respondents not being aware of the mandatory requirement of consent from the participants for using their biological samples for study purpose.

Table No. 3: The responses in percentage regarding case scenarios regarding Knowledge involving various aspects of research

\begin{tabular}{|c|l|c|c|}
\hline S No & Case scenarios regarding Knowledge involving various aspects of research & Correct & Wrong \\
\hline 1 & Case 1: Informed consent describing risks and benefits & 332 & 83 \\
\hline 2 & Case 2: Research involving children & 277 & 138 \\
\hline 3 & Case 3: Retrospective research on stored samples originally collected for clinical purposes & 215 & 200 \\
\hline 4 & Case 4: Maintaining confidentiality in Health research & 358 & 57 \\
\hline
\end{tabular}

\section{Discussion}

The participants of the questionnaire survey showed a high acceptance for the requirement of research ethics committee and were had a truistic opinion that the institutional ethics committees would be very helpful and useful for promoting health research and are imperative for appraisal of the health research projects.

It was very evident from our study that most of the respondents were aware of the research ethics committee's importance in doing health research. Majority of our respondents showed that they already had prior knowledge about research ethics and have undergone some type of training Though about $67 \%$ of the population have shown that they had prior training in research ethics. The proportion of the respondents 141
(34\%) who have mentioned that they have not attended any type of research training, were all post graduate students. Whereas the professors, reader/associate professors, senior lecturers have mentioned they had attended any type of research training programs earlier.

The results of our study regarding acceptance of regional ethics committee by the medical and dental speciality of various academic positions at multicentric level was found to be very complaisant with findings of the study by Hadir F. El-Dessouky et al. (2007) ${ }^{3}$.

The findings of our study congruous with the study done by R. Sudhakara Reddy et al $(2018)^{4}$ Their suggestion regarding having a teaching module in research ethics was found to be consistent with the results of our study done on both medical and dental speciality 
and at multicentric study unlike the single centre study involving only the dental professionals by R Sudhakara Reddy et $\mathrm{al}^{4}$.

We conducted this study as there were only very few studies done earlier including all the various parameters $6,7,8$.

We had several limitations in our study. Firstly, for our study the responses from the participants were obtained through a convenience sampling. Hence, due to potential selection bias, the responses of our participants might not be representative of their respective faculties and post graduate students in each of the participating institutions.

Despite these limitations, our study provided the details about faculty and post graduate students in the medical and dental speciality the knowledge and awareness with ethical principles that steer the conduct of research and their awareness of the roles of the institutional ethics committees, the extent of their previous training in research ethics and their attitudes towards issues in research ethics and the towards institutional ethics committees.

The findings of our study highlight the need for conducting a well-structured research ethics training to faculty and post graduate students of the medical and dental speciality possibly as part of an obligatory module during their academic progress and postgraduate course ${ }^{9,10}$. The participants with prior training in ethics comparatively with participants without training in research ethics were more likely to agree with several questionable practices regarding research ethics. ${ }^{11,12}$

\section{Conclusion}

The results of the study also helped us to assess the requirement for a regular teaching about research ethics among the faculty and students of medical and dental colleges. We recommend that the central and local health educational bodies should implement teaching of health research teaching modules in the health education in India among all the faculties and students in health institutions.

Studies should also be done at regular intervals to assess their knowledge, awareness, attitudes and practice of research ethics before and after the taring in research ethics. The information obtained from such studies will be very useful and also guide to construct improved training programs and modules on research ethics.

\section{Source of Support or Funding: Nil}

Conflict of Interest: All authors declare that they have no conflict of interest.

\section{References}

1. Creswell, J.W. Educational Research: Planning, conducting and evaluating quantitative and qualitative research (3rd ed.) (2008). Upper Saddle River: Pearson

2. GR Gillett; Ethics and dental research; Journal of Dental Research 1994;73(11):1766-1772.

3. Hadir F. El-Dessouky.Knowledge, Awareness and Attitudes about Research Ethics among Dental Faculty in the Middle East: A Pilot Study. International Journal of Dentistry 2011; 1:13

4. R. Sudhakara Reddy, K. Ramya, M.A.V.K. Raju, G. Subba Rayudu, CH. Sai Kiran, K. Jyothirmai. Knowledge, awareness and attitudes about research ethics among dental professionals in a dental institution of south India. J Educ Ethics Dent 2013; $3: 34-9$

5. Gopinath NM. Knowledge awareness and attitude about research ethics among dental faculties in India.J Contemp Dent Pract2014;15(5):608-13.

6. Kiran Kumar Mallela, Rachit Walia, Chaitra Devi TM, Maneesha Das, Shipra Sepolia, Priyank Sethi. Knowledge Awareness and Attitude about Research Ethics among Dental Faculties in India. The Journal of Contemporary Dental Practice 2014;15(5):608-613.

7. Shravani G Deolia, KVV Prasad, Kumar Gaurav Chhabra, Ramya Kalyanpur, ShrivardhanKalghatgi. An Insight into Research Ethics among Dental Professionals in A Dental Institute, India- A Pilot Study. Journal of Clinical and Diagnostic Research 2014;8(9):609

8. N. Kandeel, Nahed M. Ali, Heba Kassem, Maged El-Setouhy, MervatElshabrawyElgharieb, Magda Darwish and Malini Moni. A Multicenter Study of the Awareness and Attitudes of Egyptian Faculty towards Research Ethics: A Pilot Study. Journal of Empirical Research on Human Research Ethics 2011;6(4): 99-108.

9. Kjellström S, Ross S N, Fridlund B. Research ethics in dissertations: ethical issues and complexity of reasoning. J Med Ethics 2010;36(7):425-30. 
10. Munung NS1, Tangwa GB, Che CP, Vidal L, Ouwe-Missi-Oukem-Boyer O. Are students kidding with health research ethics? The case of HIV/AIDS research in Cameroon. BMC Med Ethics. 2012;11(13):12.

11. Sana Loue. The Impact of a Research Ethics
Training Program: Romania as a Case Study. J Empir Res Hum Res Ethics 2014; 9(5): 46-55.

12. Nikravanfard N, Khorasanizadeh F, Zendehdel K. Research Ethics Education in Post- Graduate Medical Curricula in I.R. Iran. Dev World Bioeth 2017;17(2):77-83. 